
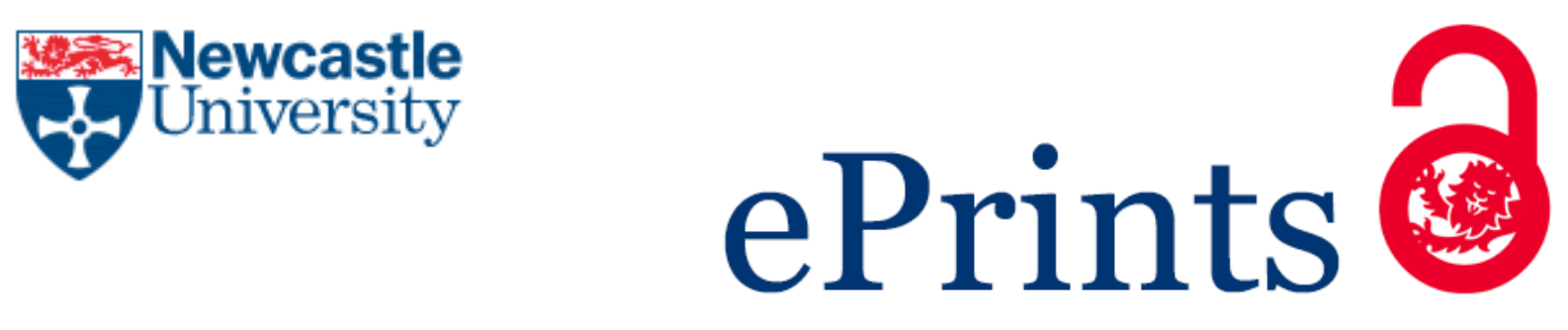

Ali SH, Giurco D, Arndt N, Edmind N, Brown G, Demetriades A, Durrheim E, Eriquez MA, Kinnard J, Littleboy A, Meinert LD, Oberhänsli R, Salem J, Schodde R, Schneider G, Vidal O, Yakovleva N.

Mineral supply for sustainable development requires resource governance. Nature 2017, 543(7645), 367-372.

\title{
Copyright:
}

This is the authors' accepted manuscript of an article that was published in its final definitive form by Nature, 2017.

DOI link to article:

https://doi.org/10.1038/nature21359

Date deposited:

$30 / 03 / 2017$

Embargo release date:

16 September 2017 
Accepted version of the paper. The full paper is available from Nature -

http://www.nature.com/nature/journal/v543/n7645/full/nature21359.html

Full reference:

Ali SH, Giurco D, Arndt N, Edmind N, Brown G, Demetriades A, Durrheim E, Eriquez MA, Kinnard J, Littleboy A, Meinert LD, Oberhänsli R, Salem J, Schodde R, Schneider G, Vidal O, Yakovleva N. Mineral supply for sustainable development requires resource governance. Nature 2017, 543, 367-372.

\section{Mineral Supply for Sustainable Development Requires Resource Governance}

Authors: Saleem H. Ali ${ }^{1,2,3}$, Damien Giurco ${ }^{4}$, Nicholas Arndt ${ }^{5}$, Edmund Nickless ${ }^{6}$, Graham Brown ${ }^{7}$, Alecos Demetriades ${ }^{8}$, Ray Durrheim ${ }^{9}$, Maria Amélia Enriquez ${ }^{10}$, Judith Kinnaird ${ }^{9}$, Anna Littleboy ${ }^{11}$, Lawrence D. Meinert ${ }^{12}$, Roland Oberhänsli ${ }^{13}$, Janet Salem ${ }^{14}$, Richard Schodde ${ }^{15,16}$, Gabi Schneider ${ }^{17}$, Olivier Vidal ${ }^{5}$ \& Natalia Yakovleva ${ }^{18}$

\section{Affiliations:}

${ }^{1}$ University of Delaware, College of Earth, Ocean and Environment, Newark DE, USA

${ }^{2}$ University of Queensland, Sustainable Minerals Institute, Brisbane, Australia

${ }^{3}$ University of Vermont, Gund Institute for Ecological Economics, Burlington VT, USA

${ }^{4}$ University of Technology Sydney, Institute for Sustainable Futures, Australia

${ }^{5}$ Institut des Sciences de la Terre, University Grenoble Alpes, France

${ }^{6}$ Geological Society of London, UK

7 Independent Exploration Geologist, London, UK

8 IUGS/IAGC Commission on Global Geochemical Baselines and EuroGeoSurveys, Athens, Greece

9 University of Witwatersrand, Johannesburg, South Africa

10 University of Para, Belem,Brazil

${ }^{11}$ Commonwealth Scientific and Industrial Research Organization (CSIRO), Australia

12 US Geological Survey, Reston VA, USA

13 Potsdam University and International Union for Geological Sciences, Germany

14 United Nations Environment Programme, Bangkok, Thailand

${ }^{15}$ Minex Consulting, Perth, Australia

${ }^{16}$ University of Western Australia, Centre for Exploration Targeting, Australia

${ }^{17}$ Namibian Uranium Institute, Windhoek, Namibia

18 Newcastle University, London Campus, UK

\section{Abstract}

Delivering the UN Sustainable Development Goals and implementing the Paris Climate Accord will require technologies that utilize a wide range of minerals in vast quantities. Metal recycling and technological change will contribute to sustaining supply, but mining must continue and grow for the foreseeable future. New linkages are needed between existing institutional frameworks to oversee responsible sourcing of minerals, trajectories for mineral exploration, environmental practices, and consumer awareness of consumption impacts. We present, through original 
analysis of a broad and eclectic set of data and demand forecasts, a multidisciplinary perspective on how best to ensure ecologically viable continuity of global mineral supply over coming decades.

\section{Introduction}

The current oversupply in world markets for raw materials ${ }^{1}$ masks a persistent underlying global challenge, namely, how to supply raw materials to an expanding global population that is expected to reach 8.5 billion by 2030 - the target date for the United Nations Sustainable Development Goals. ${ }^{2}$ Three events highlight the urgency and complexity of the challenge. First, on December 12, 2015, the COP21 agreement on climate change was formally adopted in Paris ${ }^{3}$. This adds momentum for a transition to a low-carbon society, a change that will require vast amounts of metals and minerals ${ }^{4}$. Mineral resourcing and climate change are inextricably linked, not only because mining require significant energy, but the world cannot tackle climate change without an adequate supply of raw materials to manufacture clean technologies $5,6,7$. Likewise, the UN sustainable development goals, launched in September 2015, will also require minerals for infrastructure, but scant attention has been paid to the science and policy needed to meet these targets. ${ }^{8}$ Second, the global mining industry is currently downsizing dramatically due to lower commodity prices, which will delay its response to future increases in demand. This is also derailing efforts that should be directed towards exploration for new primary resources and an improvement in the recovery efficiencies in metal recycling. Third, events such as the Samarco tailings dam collapse in Brazil, ${ }^{9}$ illustrate the consequences when mining and mineral processing is not done in an environmentally and socially responsible manner. Miners will be subject to far more stringent regulations, levied by legislators or imposed by local communities, which will prevent access to some resources and render exploitation of others more difficult and costly.

In this article, an interdisciplinary group, under the "Resourcing Future Generations" initiative of the International Union of Geological Sciences, the International Council for Science Unions and the UNESCO, evaluates these trends, and proposes measures to avert the crisis that is looming in the sphere of geological mineral exploration, recycling and the governance of supply chains.

Recent evaluations of shorter-term supply risk and criticality ${ }^{10,11,12,13}$ suggest that, over the next 2--3 decades, when the availability of metals for recycling remains low ${ }^{14}$, an unprepared minerals industry will struggle to meet demand for several metals (for example, copper ${ }^{15}$ ) for which substitutes are not readily available. In addition, specialty metals such as germanium are by-products of mining other metals, in this case zinc sulphide minerals, which contain trace amounts of germanium, and are thus dependent on the mining of their host metal. Given the rapid pace of technological and demographic change, broader discussion of current and future mineral supply is needed to avoid disruptive volatility in prices and supply. To stimulate the discussion, we first evaluate various approaches for charting supply problems. The modelling in Fig. 1 shows that a peak in primary and recycled metal production for copper will not be reached before the middle of this century. However in the coming decades, supply will be tight because accelerating demand will not be 
met by increasing recycling or substitution, and because decreasing use of fossil fuels to mitigate the effect of climate change will require increasing consumption of metals.

We develop a hybrid approach supported by various research programs on resource scarcity and climate policy, using copper as an example. Copper is widely used throughout the economy in conventional and renewable electricity generation and in electric vehicles and buildings. It has major recycling potential but its end-of-life recycling rate is $\sim 60 \%$, and due to delays between manufacturing and scrapping, the recycling input rate is only about 33\% (a measure for the share of secondary sources in raw material supply $)^{16}$. The future availability of metals and other mineral products will depend both on economic and market factors (metal prices, anticipated supply and demand) and on social and environmental pressures ${ }^{17}$. We anticipate a need for greater environmental diplomacy to assure access to mineral deposits which are irregularly distributed and often occur in areas of conflict $^{18}$.

\section{Challenges facing future mineral supply}

Future supply challenges for copper are illustrated in Figures 1 and 2. When considering future supply, geologists estimate the total amount of geo-potential copper available for mining. This amount comprises reserves, the term applied to deposits that are economic to mine at the present time and resources, which include already identified and undiscovered deposits that are sub-economic at present but have reasonable prospects for eventual economic extraction. In the case of copper estimates for copper resources by Kesler and Wilkinson in 2008 projected 5500 years of extraction potential up to $3 \mathrm{~km}$ subsurface depth. ${ }^{19}$ Higher selling prices and improved extraction techniques can make marginal deposits economically viable, but social conflict and environmental constraints on production can limit or deny access to resources yet to be developed. Whilst the former factors have long been taken into account when identifying accessible and economic ore deposits, consideration of the latter has been patchy. According to some surveys, the rate of discovery has slowed in the past decade as many easily accessible deposits are exhausted. The current dearth of exploration activity exacerbates the problem. ${ }^{20}$ The obligation to mine in an environmentally acceptable manner has added a vast array of regulations that has greatly increased the cost of mineral exploration and mining. In addition, the need to obtain the mining community's social licence to operate, and a scarcity of legislative, economic and governance stability in the host country, will place further constraints on mineral supply. ${ }^{21}$

Fig. 1 compares the results of modelling current and future production of copper from two sources, primary (mined) production and recycling, while assuming population stabilization projections (see Supplementary Information SI-1 for details). If population does not stabilize after 2050 and continues to grow, the demand scenario could be even higher, leading to further supply concerns. Nevertheless, the supply of metals available for recycling, combined with encouragement from governments to move towards a circular economy, is slowly decreasing the relative contribution from primary production 22 . Secondary sources will eventually displace primary production (Fig. 1) but this will not occur until the middle of the century because most of the supply of recyclable material is locked up in long-life assets. 
At least a quarter of known copper resources are in countries with less than satisfactory governance, as assessed using the Natural Resource Governance Index of $2014^{23}$ (see details in the Supplementary Information SI-2) which quantifies the quality of "institutional and legal setting, reporting practices, safeguards and quality controls, and enabling environment". Although the quality of governance will no doubt change in the future, and some corrupt or incompetent governments will be replaced, the global trend provides little evidence that the problem will disappear in the near future. Production from countries with poor governance will certainly be needed to meet global demand and this issue will need to be taken into account. An analysis of major copper mines worldwide (Fig. 2) shows long delays in project approvals in many of the locations where copper will be sourced in the future. Fig. $2 a$ shows that, depending on the location, the average lead-time between discovery and development is 13 to 23 years and the rate of conversion seems to be slowing (Fig. $2 b)$. When combined with the need to satisfy regulations that assure that mineral exploration and mining is done in an environmentally and socially acceptable manner, the figure demonstrates that the mining industry is not in a strong position to quickly find and bring on stream new capacity to meet a shortfall in production.

\section{Fostering further exploration and recycling}

Our analysis also reveals that the incentives for investment in exploration are not always aligned with societal needs and constraints. The market determines investment based on short-term returns rather than long-term scarcity planning. Fig. 3 shows the historical investment in exploration over time, as well as a wide variation in the preferred commodity. The high investment in uranium during the Cold War was due to government subsidies, while the recent emphasis in gold is due to high return on investment. In both cases, exploration was stimulated by high commodity prices.

As Fig. 3b also shows how the spurt of investment in exploration during the recent resource boom was followed by a steep decline since 2012 due to a fall in metal prices triggered by a weakening of demand. Metal prices remain low and exploration investment in such a climate is unattractive.

The supply of some metals from recycled sources has the potential to increase, due in part to government incentives to move towards a circular economy that minimises material usage and maximises the use of recycled materials ${ }^{24,25}$. However, the supply of recycled material is limited by the time the metals are tied up in industrial infrastructure and consumer products. The more durable the infrastructure, the less available the metal supply for recycling for other uses. Residence times of metals in infrastructure are highly variable, and depend on design practices and goals ${ }^{26}$. Durability has its own environmental benefits in terms of material and energy conservation, but high durability counters the recycling imperative to meet metal demand. End-of-life recycling rates vary from about $1 \%$ for potentially critical metals like the Rare Earth Elements (REE) to $55 \%$ or so for aluminium ${ }^{27}$ and $70 \%$ or more for iron ${ }^{28}$. To meet growing demand once the global economy improves, mining will need to continue to the foreseeable future.

\section{Global Resource Governance Needed}


The development of renewable energy sources and other high-technology applications will require new infrastructure that will consume a different mix of minerals from current applications, including not only "critical" 29 metals such as the rare earths, but also vast amounts of common commodities such as copper, steel and cement ${ }^{2,3,4}$. Of major concern is a potential period when primary metal production may peak and start to decline before the social and capital infrastructure for secondary metal production will allow recycling to contribute substantially to supply (Figure 1).

Three policy paths have been explored to understand and assure an adequate supply of metals and other mineral products. First, certain countries have focused on boosting supply through a national security agenda from sources that are politically more feasible to access. ${ }^{30,31}$ The U.S. Department of Energy's Critical Materials Institute was established through a $\$ 120$ million grant to a consortium led by Ames National Laboratories in 2013. The European Union has established the European Institute of Technology Knowledge and Innovation Community on Raw Materials, and launched programs such as the European Innovation Partnership on Raw Materials and the ERA-MIN network. The European Commission identifies twenty raw materials as critical for the EU economy based, on their economic importance for European industries and their high supply risk (see Supplementary Information $\mathrm{SI}-3)^{32}$. The Geological Surveys of the United States ${ }^{33}$ and Britain ${ }^{34}$ came up with similar lists. It should be noted that there is no uniformly agreed definition of criticality; country lists vary depending on how the nation and its industries use various materials. ${ }^{35}$

Second, international programmes have assembled data on resource demand and governance of natural resources. ${ }^{36}$ The International Resource Panel of the United Nations Environment Programme and the Intergovernmental Forum on Mining, Minerals, Metals and Sustainable Development are key examples. Both have undertaken important work on mineral availability and governance but to date they have largely focused on knowledge exchange with limited regard to developing policy for resource scarcity. The World Resources Forum and Future Earth have brought together scholars, industry and policymakers to grapple with the science of resource scarcity but have no policy-making power.

Third, whereas industry organisations such as the International Council on Metals and Mining have worked on environmental and social aspects of present and future mineral supply ${ }^{37}$, projections of future mineral resources have been the purview of exploration divisions of companies and national geological surveys. Although there may be common metallurgical processes between them, mining and recycling operations remain largely separate in their corporate management, the former carried out mainly by private mining companies; the latter by a different group of companies or by government agencies. Given the common trading markets for metals, whether from mined or recycled sources, there are further opportunities for harnessing ecologically efficient sourcing pathways for metal users.

Only after collection is there convergence, when refineries controlled by mining companies treat both primary and recycled materials. Without better anticipation of the future aspirations of society, and a better knowledge of the ability of our planet to supply the needed raw materials, we remain at the mercy of short-term decision 
making. Much of the debate about long term criticality remains in the research/policy space, is not reflected in the markets and has not yet been taken up effectively by governments and industry at the global scale.

\section{Actions for sustainable mineral sourcing}

The International Community must actively plan for the next few decades when mineral supply threatens to be inadequate. This planning needs to consider the vulnerable but flexible nature of mineral resources and the global dependence on critical minerals. An international process is needed to mitigate the shocks of future supply crises, which could be undertaken through a covenant ${ }^{38}$ or even a treaty. ${ }^{39}$ The G7 (an alliance of seven major industrialized democracies) has tentatively recognized the governance vacuum on raw materials through establishing "alliance on resource efficiency," in 2015. However, none of the current international agencies has a mandate to plan, oversee or realise efficient and effective exploitation of mineral resources. Even though there is considerable fatigue with too many international treaties, as noted by major resource powers such as China ${ }^{40}$, we propose that a linkage between the International Resource Panel and the Intergovernmental Forum on Mining, Minerals, Metals and Sustainable Development could use existing treaty mechanisms for more effective resource planning. The recently established United Nations Environment Assembly ${ }^{41}$ could play a convening role to help ensure that ecological constraints are duly incorporated into effective planning. Six specific measures should be considered:

1. Reach consensus on international targets for global mineral production: As with the targets for emissions reductions in COP 21, standards should be set to assure that mining is conducted with maximum efficiency and minimal negative impact on the environment and society. Design specifications for modularity of products that can assist in reaching targets for recycling, product design and modularity, waste harvesting, and stockpiling should be established at the global rather than national level, the latter being more focused on internal security. These targets should be dynamic and flexible; they should change in response to technological developments, but must remain part of an integrated planning process.

2. Monitor impacts of mineral production and consumption: Establish a system for tracking mineral use along the entire value chain, from source to end-oflife, perhaps based on the "fingerprinting" developed by the German Geological Survey for tantalum ${ }^{42,43}$ Incorporate a global chain-of-custody programme similar to that of the food industry. Promote domestic production and consumer cognizance of mineral use incorporating a notion of "metal miles"; i.e. reduction of the environmental cost of transport through increased consumption of local products. Global communities should be accountable for environmental and social consequences of their consumption, not only of food but also of minerals.

3. Improve coordination of mineral exploration: Private-public cooperation is needed to develop new techniques for mineral exploration in new locations, from deep in the crust to the bottom of the ocean, drawing on lessons from programs such as Australia's UNCOVER: Searching the Deep Earth program or the European Union's Blue Mining initiative for deep oceanic mineral deposits. Data sharing between industry and geological surveys is also 
essential. Geophysical and geochemical data both need to be shared in greater detail through dynamic databases (See SI-5 for example of European geochemical database efforts).

4. Support investment and research into new mineral extraction technologies:

Technology to maximise efficiency, minimise waste and reduce the consumption of water should be shared more effectively through intellectual property arrangements like the reforms proposed in pharmaceutical patent sharing for development outcomes. ${ }^{44}$ Extraction processes should be improved. Typical copper grades are less than $1 \%$ of the total mass and the recovery rate of this small amount should be maximized. In addition, all valuable metals contained in the ore should be recovered rather than ending up in the tailings dam (e.g. indium or germanium in $\mathrm{Zn}$ ores, or Ga in bauxite). Lunar $^{45}$ and asteroid mining, while plausible for long-term planning, as exemplified by the recent unmanned Chinese mission to moon and private efforts like the Lunar-X prize, face techno-economic and regulatory uncertainty ${ }^{46}$ and most probably will not supplant mining on Earth for many decades.

5. Harmonise global best practices for responsible mineral resource development: Mineral deposits are irregularly distributed and their locations are fixed by geology. Thus, the value of these mineral resources must be assessed in the context of other land uses. Technological evolution needs to be reinforced by establishing global practices that balance mining and mineral treatment with biodiversity protection, agriculture and urbanisation, and other land and water uses. Good environmental practice, proactive and effective stakeholder engagement, and co-existence of mining and other land uses must form the basis of sustainable mineral exploitation. To achieve this, better coordination between industry and governments will be needed.

6. Develop maps and inventories showing the availability of recyclable metals: These maps would show the locations and status of stocks of in-use metals available for future use and recycling, just as geoscience agencies map the locations of primary ores. In this way, companies seeking to utilise these resources can assess their potential composition and availability over time. Unlike primary ores, which take a 'commodity focus' based on a single metal (e.g. Cu) or several co-products (e.g. $\mathrm{Zn}, \mathrm{Pb}, \mathrm{Ag}$ ), recycling demands a 'product focus' that defines the recycling potential of multiple metals contained in the product. Given the huge variation in recyclability of metals, which depend on the product in which the metal is used as well as the future demand for the meal, establishing internationally recognised standards for recyclability would be an important development.

We recognize that in many cases commodity pricing signals run contrary to ecological goals. Regulatory mechanisms would be needed for companies to focus on longer-term resource conservation planning. Furthermore, to meet these challenges, we advocate an early warning system, based on rigorous analysis of data, comprising a series of alarms, perhaps through the international mechanisms noted: (1) geological alarms - do we have sufficient reserves? (2) time lag alarms we know the reserves are out there, but can they be developed in time? (3) governance alarms - we know where they are, but can they be sustainably mined? (4) technological alarms - novel and unanticipated uses for previously unwanted metals, (e.g. Te, Ge, In), (5) environmental alarms - are the risks to local 
ecosystems and populations too high? (6) social alarms - will, or should, local populations resist mining? (7) geopolitical alarms - will land ownership or other uses (agriculture, parks, reserves, other industry) preclude mining? (8) business risk alarms - will changes in tax and investment rules or political instability make mining uneconomic?

\section{BOX 1: The International Resources Panel - Metals Flows Group}

The International Resources Panel was established in 2007 as part of the United Nations Environment Programme, in the context of sharp growth in demand for natural resources, population growth, and rising incomes in developing countries, leading to strong international material flows. The panel's mission is to consolidate and evaluate scientific data, with the aim of providing global guidelines for the sustainable management of natural resources. One of its first reports was "decoupling" 47 which summarises the central message of the panel: the need to produce products and services with less environmental impact and degradation. Key reports thus far to inform better resource governance in the sector are as follows:

- Metal Stock in Society - Scientific Synthesis (2010). This report concludes that metal stocks in society are increasing continuously. These "mines above ground" could contribute to decouple resource use from economic growth if the resources are effectively recycled. 48

- $\quad$ Recycling Rates of Metals - a Status Report (2011). This report provides an overview on current knowledge of recycling rates for sixty metals including an estimate of how efficiently metals are retained for a second or third use within modern technological systems. ${ }^{49}$

- $\quad$ Metals Recycling - Opportunities, Limits, Infrastructure (2013). The report shows that sustainable metal management requires more than improving recycling rates. The whole mindset on recycling of metals must be changed, moving from a material-centric approach to a product-centric approach. ${ }^{50}$

- Environmental Risks and Challenges of Anthropogenic Metal Flows and Cycles (2013) This report explores the ecological impacts of the exploration, development, extraction, and processing of metals but does not consider social issues or environmental aspects. ${ }^{51}$

- A working paper resulting from a workshop on evaluation of mineral reserves - Estimating Long-Run Geological Stocks of Metal ${ }^{52}$ concludes that reserve base estimates are lacking for many metals of interest, and it is not possible at present to accurately estimate the extractable global resource for any metal.

- $\quad$ Global Material Flow and Resource Productivity (2016). The report considers linkages between the world economy, population and material use over four decades (1970-2010) based on "a new and authoritative database of global material extraction and a revised database for materials trade." 53

Two further reports are in progress. The first will be a research study of the supply and demand from the present until 2050 for some of the metals used in large quantities in modern society. The second will draw upon all the previous reports to develop policy recommendations related to the use, reuse, and loss of metals. 


\section{Planetary Policy for Minerals}

International Environmental Policy is currently missing the resource dimension for meeting both ecological and development targets. ${ }^{54,55}$ There is a plethora of international organizations to promote ecologically efficient development such as the Global Green Growth Institute and the International Renewable Energy Agency. Yet the resource needs for carrying out their agendas should be evaluated in terms of mineral needs through a coherent planning process, based on the parameters we discussed in this article. Minerals are a fundamental planetary resource and should be a base tenet of environmental policy development. Global coordination is needed to ensure that minerals are produced in the most ecologically and economically efficient way. Further research, and institutional collaboration between the private and public sectors, is needed to develop innovative methods to locate and extract future mineral resources. Mining and recycling will need clear metrics of ecological and economic performance. This coordination could be provided by nascent organisations such as the International Resource Panel, Future Earth and the Intergovernmental Forum on Mining, Minerals, Metals and Sustainable Development in partnership with epistemic communities of environmental organisations, such as the International Union for Conservation of Nature. Ultimately, international legal mechanisms may be needed to anticipate and respond to future mineral availability constraints.

\section{REFERENCES}

${ }_{1}^{1}$ Rankin, J. Brussels steel summit fails to find answer to oversupply problem. The Guardian (18 April 2016), https://www.theguardian.com/business/2016/apr/18/brussels-steel-summit-fails-find-answeroversupply-problem [accessed, June, 2016]

2 UNFPA. Revision of Population Prospects. (United Nations, 2015).

3 UNFCCC. Adoption of the Paris Agreement by the President: Paris Climate Change Conference. (United Nations 2015). http://unfccc.int/resource/docs/2015/cop21/eng/l09r01.pdf [accessed, August, 2016].

${ }^{4}$ Vidal, O., Goffé, B. \& Arndt, N. Metals for a low-carbon society. Nature Geoscience 6, 894-896 (2013).

5 3.Alonso, E. et al. Evaluating Rare Earth Element Availability: A Case with Revolutionary Demand from Clean Technologies. Environ. Sci. Technol. 46, 3406-3414 (2012).

This article provides detailed analysis of the rapid projected rise in rare earths mineral demand over the next 3 decades as a function of the growth in clean energy technologies.

${ }^{6}$ Zepf V., Reller A., Rennie C., Ashfield M. \& Simmons J., B.P. Materials critical to the energy industry. (BP Publications, 2014).

${ }^{7}$ Larcher, D. \& Tarascon, J-M. Towards greener and more sustainable batteries for electrical energy storage. Nature Chem. 7, 19-29 (2015).

${ }^{8}$ Bringezu, S., Potocnik, J. Schandl, H., Lu, Y., Ramaswamy, A., Swilling, M. and Suh S. Multi-scale governance of sustainable natural resource use - challenges and opportunities for monitoring and institutional development at the national and global level." Sustainability 8, 778 (2016)

${ }^{9}$ Phillips, D. Brazil's mining tragedy: was it a preventable disaster? The Guardian, (25 Nov 2015), https://www.theguardian.com/sustainable-business/2015/nov/25/brazils-mining-tragedy-dampreventable-disaster-samarco-vale-bhp-billiton [accessed online,August, 2016].

${ }^{10}$ European Commission. Report on Critical Raw Materials for the EU. ( European Commission, 2014).

11 Graedel, T. E., Harper, E.M., Nassar, N.T. and Reck, B.K. On the materials basis of modern society. Proceedings of the National Academy of Sciences of the United States of America, 112,62956300 (2013).

12 Moss, R.L., Tzimas, E., Kara, H., Willis, P. and Kooroshy, J. Critical Metals in Strategic Energy

Technologies Assessing Rare Metals as Supply-Chain Bottlenecks in Low-Carbon Energy

Technologies. JRC Scientific and Technical Report. EUR 24884 EN - 2011 (European Union, 2011). 
${ }^{13}$ Frenzel, M., Tolasano-Delgado, R., Gutzmer, J. . Assessing the supply potential of high-tech metals - A general method. Resources Policy 46, 45-58 (2015).

This paper presents a novel methodology for estimating supply using Monte-Carlo type statistical simulations of repeated recovery of technology metals from product supply chains. 14 International Resource Panel, 2007. Metals Recycling: Opportunities, Limits and Infrastructure. Nairobi: UNEP.

${ }^{15}$ Elshkaki, A., Graedel, T.E., Ciacci, L., Reck, B. Copper demand, supply, and associated energy use to 2050. Global Environmental Change 39, 305-315 (2016).

16 The World Copper Fact Book 2015, published by the International Copper Study Group (2015). http://www.icsg.org/index.php/component/jdownloads/viewdownload/170/2092 [accessed, August, 2016].

${ }^{17}$ Franks, D., Davis, R., Bebbington, A J., Ali, S H., Kemp, D. and Scurrah, M. Conflict translates environmental and social risk into business costs. Proceedings of the National Academy of Sciences of the United States of America, 111, 7576-7581 (2014).

An evaluative study of the economic cost of social conflict estimated through a detailed analysis of mining projects worldwide through interviews with managers who provided a delineation of the causes of the conflicts in environmental and social terms.

${ }^{18}$ Susskind, L. and Ali, S.H. Environmental Diplomacy: Negotiating More Effective International Agreements. (Oxford University Press, 2014).

${ }^{19}$ Kessler, S.E \& Wilkinson, B.H. Earths copper resources estimated from tectonic diffusion of porphyry copper deposits. Geology 36, 255-258.

${ }^{20}$ Rio Tinto Corporation. Global Exploration Spend and Historic Discovery Rate. (Slide 5 of

Presentation at Citigroup Investment Conference, 2016). Available online: http://www.riotinto.com/documents/160627 Presentation Citigroup exploration conference Stephen McIntosh.pdf [Accessed, November, 2016].

${ }^{21}$ Meinert, L.D., Robinson, G.R. and Nassar, N.T. Mineral Resources: Reserves, Peak Production and the Future. Resources 5,1-14 (2016).

${ }^{22}$ Gregson, N., Crang, M., Fuller, S. and Holmes, H. Interrogating the circular economy: the moral economy of resource recovery in the EU. Economy and Society 44, 218-243 (2015).

${ }^{23}$ The Methodology by which the Natural Resource Governance Index is calculated can be found at http://www.resourcegovernance.org/resource-governance-index [Accessed, August, 2016].

${ }^{24}$ Hatayama, H., Daigo, I. and Tahara, K., Tracking effective measures for closed-loop recycling of automobile steel in China. Resources, Conservation and Recycling, 87, 65-71(2014).

${ }^{25}$ Gregson, N., Crang, M., Fuller, S. and Holmes, H. Interrogating the circular economy: the moral economy of resource recovery in the EU. Economy and Society 44, 218-243 (2015).

${ }^{26}$ Angrick, M., Burger, A., Lehmann, H. Eds. Factor X, Eco-Efficiency in Industry and Science. (Springer, 2013)

${ }^{27}$ Liu, G., C. E. Bangs, and D. B. Muller. Stock dynamics and emission pathways of the global aluminium cycle. Nature Clim. Change 3, 338-342 (2013)

${ }^{28}$ Graedel, T. et al. What Do We Know About Metal Recycling Rates? Journal of Industrial Ecology 15, 355-366 (2011).

29 Graedel, T. E., Harper, E.M., Nassar, N.T., Nuss, P. and Reck, B.K., Criticality of Metals and Metalloids. Proceedings of the National Academy of Sciences,112, 4257-62 (2015).

A comprehensive evaluation of key limiting factors that lead to potential mineral security concerns from the point of view of mineral demand and supply bottlenecks.

${ }^{30}$ Naden, J. Science and Implementation Plan. Security of Supply of Mineral Resources (SoS

Minerals) Research Programme 2012-2017. Sustainable Use of Natural Resources (Natural

Environment Research Council, UK, 2013). Available from:

http://www.nerc.ac.uk/research/funded/programmes/minerals/science-and-implementation-plan/

${ }^{31}$ Gunn, G.\& Bloodworth, A. Briefing: minerals security of supply: a geological perspective.

Proceedings of the ICE - Waste and Resource Management, 165,171-173 (2012).

32 European Commission Report on Critical Raw Materials for the EU. Report of the Ad hoc Working Group on Defining Critical Raw Materials. (European Commission, 2014).

${ }^{33}$ National Science and Technology Council. Assessment of Critical Minerals: Screening Methodology and Initial Application. (The White House, 2016). Available online:

https://www.whitehouse.gov/sites/default/files/microsites/ostp/NSTC/csmsc assessment of critical minerals report 2016-03-16 final.pdf

${ }^{34}$ British Geological Survey. World Mineral Production 2006-10 (British Geological Survey, 2012).

Available from: https://www.bgs.ac.uk/downloads/start.cfm?id=2255 
35 Gloser, S., Tercero Espinoza, L., Gandenberger, C., Faulstich, M. Raw material criticality in the context of classical risk assessment. Resources Policy 44,35-46 (2015).

${ }^{36}$ Consider the large body of work prepared by the International Resources Panel, accessible at: http://www.unep.org/resourcepanel/

${ }^{37}$ Refer to ICMM web site for details on their publications http://www.icmm.com

38 Wilts, H., Bleischwitz, R., An International Metal Covenant: A Step Towards Global Sustainable Resource Management, in: Angrick, M., Burger, A., Lehmann, H. (Eds.), Factor X, Eco-Efficiency in Industry and Science. (Springer, 2013).

39 Henckens, M.L.C.M, Driessen, P.P.J., Ryngaert, C., Worrell, E. The set-up of an international agreement on the conservation and sustainable use of geologically scarce mineral resources.

Resources Policy 49 (2016): 92-101.

Bold article that makes the case for an international agreements on minerals based on both intergenerational equity and resource conservation arguments with a suggested quota development model.

40 Preston,F., Bailey, R., Bradley, S., Wei, J., Zhao, C. Navigating the New Normal: China and Global Resource Governance. (Chatham House and Development Research Centre of the Chinese State council, 2015).

${ }^{41}$ Desai, M. The Advent of the United Nations Environment Assembly. Insights from the American Society of International Law. 19,(2015).

${ }^{42}$ Melcher, F., Graupner, T., Sitnikova, M., Oberthür, T., Henjes-Kunst F., Gäbler, E. and Rantitsch, G. Analytical fingerprint for tantalum ores from African deposits. Geophysical Research Abstracts, 11, EGU2009-2452,(2009).

${ }^{43}$ Franken, G., Vasters , J., Dorner , U., Melcher, F., Sitnikova, M. , and Goldmann, S. Certified

Supply Chains in Mineral Production. In R. Sinding-Larsen and F.-W. Wellmer (eds.), Non-

Renewable Resource Issues: Geoscientific and Societal Challenges. (Springer, 2012).

${ }^{44}$ Correa, C. Integrating Public Health Concerns into Patent Legislation in Developing Countries.

(Geneva, Switzerland: The South Centre, 2000).

${ }^{45}$ Crawford, I. A. Lunar Resources: A Review. Progress in Physical Geography 39,137-167(2015).

${ }^{46}$ Roth, S.E., Developing a Law of Asteroids: Constants, Variables, and Alternatives. Columbia Journal of Transnational Law, 54, 827-872(2015).

47 International Resource Panel. Decoupling Natural Resource Use and Environmental Impact from Economic Growth. (UNEP, 2011).

http://www.unep.org/resourcepanel/Portals/50244/publications/Decoupling_Report_English.pdf

48 International Resource Panel. Metal Stocks in Society: A Scientific Synthesis. (UNEP, 2010).

http://www.unep.org/resourcepanel/Portals/50244/publications/UNEP_report1_Stocks_100920.pdf

49 International Resource Panel. Recycling Rates of Metals: A Status Report. (UNEP, 2011).

http://www.unep.org/resourcepanel/Portals/50244/publications/UNEP_report2_Recycling_130920.pdf

50 International Resource Panel. Metals Recycling: Lessons, Opportunities and Infrastructure. (UNEP, 2013).

http://www.unep.org/resourcepanel/Portals/50244/publications/UNEP_report2b_RecyclingOpportuniti es_130919.pdf

51 International Resource Panel. Environmental Risks and Challenges of Metal Flows and Cycles.

(UNEP, 2015).

http://www.unep.org/resourcepanel/Portals/50244/publications/UNEP_report3_Environmentallmpacts 130920.pdf

52 International Resource Panel. Estimating Long-term Geological Stocks of Metals. (UNEP, 2011).

http://www.unep.org/resourcepanel/Portals/24102/PDFs/GeolResourcesWorkingpaperfinal040711.pdf

53 International Resource Panel. Global Material Flow and Resource Productivity. (UNEP, 2016).

http://unep.org/documents/irp/16-00169_LW_GlobalMaterialFlowsUNEReport_FINAL_160701.pdf

${ }^{54}$ Gielen, D., Boshell, F. \& Saygin, D. Climate and energy challenges for materials science. Nature

Mater. 15, 117-120 (2016).

55 Jeffries, E. Coming Clean. Nature Clim. Change 5, 93-95 (2015). 
Supplementary Information is available in the online version of the paper

Acknowledgments Daniel Nyanganyura of the International Council for Science and Fabio Masotti of Vale Corporation provided valuable comments leading to this paper. Steve Mohr of the University of Technology Sydney assisted with the model output results presented. The financial support provided by UNESCO, IUGS, ICSU and logistical support provided by the Namibian Geological Survey is duly acknowledged.

Author Contributions S.H.A. designed and synthesized the written article with N.A. and D.G.; E.N. led S.H.A., D.G., N.A., R.O., L.M., A.D., M.A.E., J.S., G.B., N.Y., A.L., G.S., J.K., R.D. to develop the analytical framework and policy response recommendations through consensus; O.V. and N.A. contributed data for Figure 1 and supplementary material in SI-1; D.G. contributed supplementary material in SI-2; R.S. contributed data for Figures 2 and 3 and supplementary material in SI-4. A.D. contributed supplementary material SI-5 and provided commentary on geochemical database and other existing tools and their data deficits. M.A.E. and J.S. prepared Box 1.

Author Information Reprints and permissions information is available at www.nature.com/reprints. The authors declare no competing financial interests. Readers are welcome to comment on the online version of the paper. Correspondence and requests for materials should be addressed to S.H.A. (saleem@alum.mit.edu)

Figure 1: Modelled primary (dashed black line) and secondary (dashed grey line) copper production to 2100 in megatonnes (million metric tonnes). The black continuous line shows the historical data of primary 23,24 and the grey continuous line shows recycled copper production (1966-2010), respectively. The fine black line is the sum of the modelled primary and secondary production. The thin dashed line is the modelled primary production of the Northey et al projection of primary production (comparison used with permission from Northey et al). ${ }^{24}$ Further information on modeling methods can be found in the Supplementary Information SI-1, together with graphs of the evolution of copper reserves through time (Fig. S1), annual endof-life copper generated (Fig. S2) and stocks in use (Fig S3).

Figure 2: Delays in approved copper projects worldwide based on year of discovery. The size of the sphere indicates the projected size of the extractable deposit.

Figure 3: Proportion of exploration investment differentiated by metal $(A)$ and expenditure; and total investment amount differentiated by region (B) over time. 